\title{
Density and Surface Tension Polytherms and Isotherms of Molten Lead-Sodium Alloys
}

\author{
Karamurzov B.S. \\ Kabardino-Balkarian State University \\ named Kh.M. Berbekov \\ Nalchik, Russia \\ bsk-1947@mail.ru \\ Kutuev R.A. \\ Chechen State University, \\ Complex R\&D Institute of the Russian Academy of \\ Sciences, Grozny, Russia. \\ kra-07@mail.ru \\ Ponezhev M.Kh. \\ Kabardino-Balkarian State University \\ named Kh.M. Berbekov \\ Nalchik, Russia \\ m.ponegev@rambler.ru
}

\begin{abstract}
Polytherms of density and surface tension of lead alloys with minor sodium percentages were studied in heating mode in a range from $\mathrm{Pb}-\mathrm{Na}$ melting temperature to $650^{\circ} \mathrm{C}$ under the atmosphere of pure Grade A He (99.995\%). It has been established that density and surface tension decrease with increased temperature, while increasing sodium content in the alloys to $4 \%$ wt leads to a significant decrease in surface tension.
\end{abstract}

Key words $\longrightarrow$ surface tension, polytherm of density, $\mathrm{Pb}-\mathrm{Na}$, melted material

\section{INTRODUCTION}

Melts of lead and sodium are deemed prospective heat transfer mediums for fast-neutron nuclear reactors [1]. At that, many thermodynamic properties of the $\mathrm{Pb}-\mathrm{Na}$ system are understudied [1-5], thus, complicating the analysis of application prospects of these melts as cooling liquids. It has been established [1] that increasing the content of alkali additives in lead improves wetting of some reactor steels. However, data on polytherms of contact angle of wetting are sparse in the literature, as there are insufficient data on density and surface tension of lead alloys with low sodium content. Thus, obtaining reliable data on surface properties of this system is a timely task.

Surface tension and density of metal melts are usually measured with a sessile drop method, or with a maximum pressure in gas bubble method. In recent years, these methods underwent modernization. This is especially true of the sessile drop method [6], where new information technologies were introduced, which are also used in this work $[7,8]$.

\author{
Sozayev V.A. \\ North Caucasus Mining and Metallurgy Institute \\ (State Technological University), \\ Vladikavkaz, Russia \\ sozaeff@mail.ru
}

Shermetov A.Kh.

Kabardino-Balkarian State University named Kh.M. Berbekov,

Nalchik, Russia

shermetov-astemir@rambler.ru

Shokarov A.A.

Kabardino-Balkarian State University named Kh.M. Berbekov,

Nalchik, Russia

shokarov-aliy@mail.ru

\section{METHODS AND MATERIALS}

To study density and surface tension as functions of temperature, alloys were prepared out of Grade B4 lead and sodium $(99.9 \%)$.

The measurements were conducted using the sessile drop method in the temperature interval from the melting point of the $\mathrm{Pb}-\mathrm{Na}$ alloys to $650{ }^{\circ} \mathrm{C}$ in the atmosphere of pure Grade A He $(99.995 \%)$.

The profile of the liquid metal drop (Fig. 1) was processed with the SigmaC software [2].

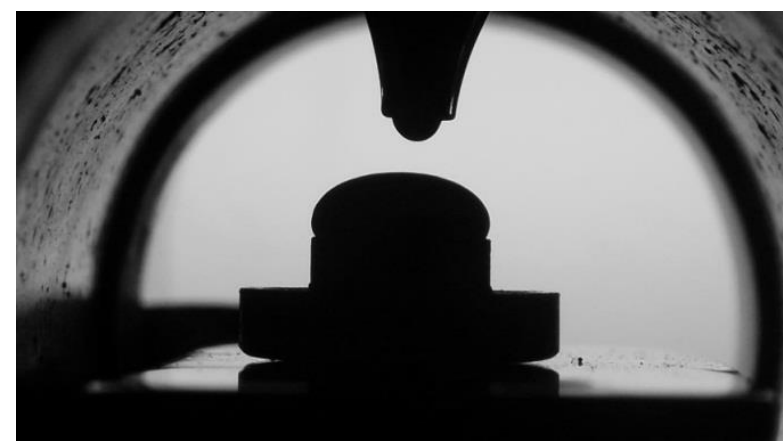

Fig. 1. A photograph of a $\mathrm{Pb}-\mathrm{Na}$ drop at $350^{\circ} \mathrm{C}$

Density and thermal expansion of the $\mathrm{Na}-\mathrm{Pb}$ systems with low lead content were studied in [3]. It has been shown that the density of the alloy increases with an increase of $\mathrm{Pb}$ concentration. 
Thermal properties of sodium-lead and potassium-lead melted systems with low percentage of lead were studied in [4]; the study revealed that the peculiarities of molar volume and thermal expansion coefficient of the sodium-lead and potassium-lead systems are linked to a trend to form intermetallides.

\section{RESULTS}

The results of the measurements are given in Figures 2, 3. In Figure 2 the thermal dependences of the melted $\mathrm{Pb}-\mathrm{Na}$ density are given. In heating mode, density decreases with increased temperature (Figure 2). Increased concentration of sodium leads to decreased density of the melts.

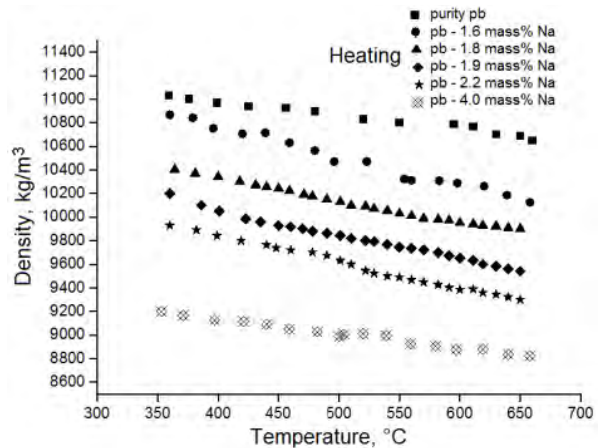

Fig. 2. Polytherms of $\mathrm{Pb}-\mathrm{Na}$ melt density for various concentrations in the heating mode.

Surface tension $\sigma(\mathrm{t})$ of the $\mathrm{Pb}-\mathrm{Na}$ melts in the heating mode decreases with increased temperature (Figure 3 ).

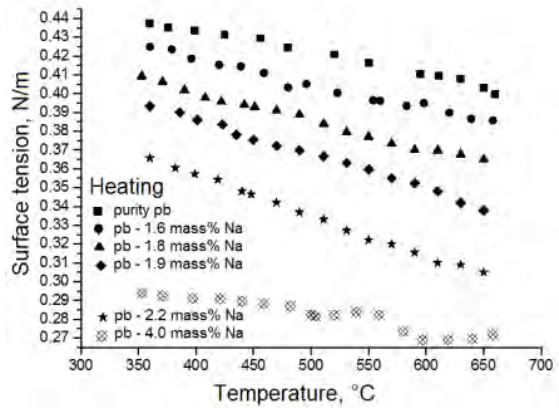

Fig. 3. Polytherms of $\mathrm{Pb}-\mathrm{Na}$ melt surface tension for various concentrations in the heating mode.

In the range of concentration from 2.2 mass. $\%$ to 4 mass. $\%$ the isotherms of density and surface tension at 500 ${ }^{\circ} \mathrm{C}$ and $650{ }^{\circ} \mathrm{C}$ show a sharp (to $30 \%$ ) reduction of both density and surface tension (Fig. 4 and 5).

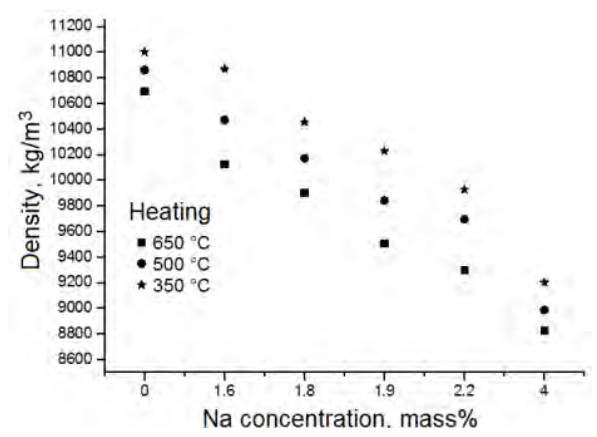

Fig. 4. Density isotherm of the Pb-Na system.

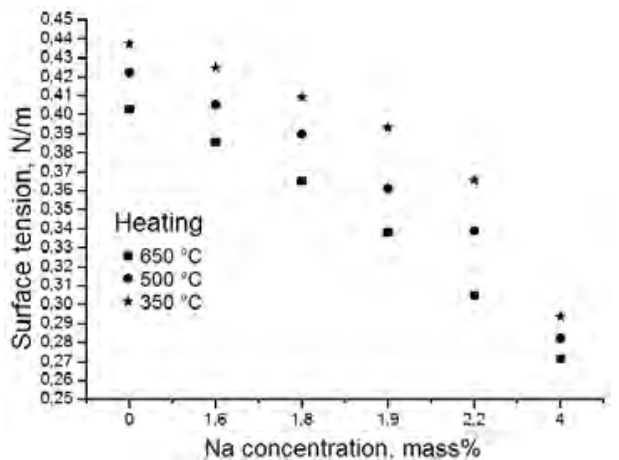

Fig. 5. Surface tension isotherm of the $\mathrm{Pb}-\mathrm{Na}$ system.

In [9], a concentration-based dependence of surface tension of the $\mathrm{Pb}-\mathrm{Na}$ system was developed for the range of concentrations from 0 to 13 at. $\%$ at $125^{\circ} \mathrm{C}$. Unfortunately, the authors of [9] did not study the temperature dependence the alloys. The concentration dependences obtained in [9] are described with the equation:

$$
\sigma=140-105 \ln (1+0.14 x)-2 x
$$

The equation (1) is analogous to one obtained by V.K. Semenchenko [10]:

$$
\sigma=\sigma_{0}-A \ln (1+B x)-D x
$$

Comparison between (1) and (2) shows that if the coefficients $\sigma_{0}$ and $A$ in these expressions depend only on temperature, then the coefficients $B$ and $D$ depend also on the concentration of the added component.

Studies of alloys with $\mathrm{Pb}-1.8 \%$ wt $\mathrm{Na}$ and $\mathrm{Pb}-1.9 \%$ wt $\mathrm{Na}$ that we conducted with an X-ray photoelectric spectroscopy on a K-ALPHA instrument of the Surface Physics, Nanosystems and Nanostructural Tecnology shared use center (a fully-integrated X-ray photoelectric spectrometer manufactured by Thermo Fisher Scientific) have shown that there were no significant changes in sodium concentration in the alloy between the before and after the experiment.

A number of works [3-5] was dedicated to studying thermophysical properties of sodium with low amount of lead added. It is related to the fact that development of sodium heat transfer mediums requires increasing their fire safety, which is attained by adding low percentages of lead. These works refined the data on density of sodium-lead alloys with high sodium content. Figures 4-5 show density and surface tension isotherms of the $\mathrm{Pb}-\mathrm{Na}$ system. From the figures, it is evident that with increased sodium concentration, both density and surface tension gradually decrease.

TABLE I. EQUATIONS OF DENSITY AND SURFACE TENSION POLYTHERMS WITH THE LEAST SQUARE METHOD

\begin{tabular}{|c|c|c|}
\hline Melts & $\boldsymbol{\rho}, \mathbf{~ k g} / \mathbf{m}^{\mathbf{3}}$ & $\boldsymbol{\sigma}, \mathbf{N} / \mathbf{m}$ \\
\hline Pure $\mathrm{Pb}$ & $\rho=11437-1.1 \cdot T$ & $\sigma=0.481-1.2 \cdot T$ \\
\hline $\mathrm{Pb}-1.6$ mass. $\% \mathrm{Na}$ & $\rho=11758-2.5 \cdot T$ & $\sigma=0.472-1.33 \cdot T$ \\
\hline $\mathrm{Pb}-1.8$ mass. $\% \mathrm{Na}$ & $\rho=11152-1.5 \cdot T$ & $\sigma=0.461-1.5 \cdot T$ \\
\hline $\mathrm{Pb}-1.9$ mass. $\% \mathrm{Na}$ & $\rho=10899-2.1 \cdot T$ & $\sigma=0.461-1.87 \cdot T$ \\
\hline $\mathrm{Pb}-2.2$ mass.\% $\% \mathrm{Na}$ & $\rho=11474-1.5 \cdot T$ & $\sigma=0.464-8.46 \cdot T$ \\
\hline $\mathrm{Pb}-4$ mass.\% $\mathrm{Na}$ & $\rho=9623-1.2 \cdot T$ & $\sigma=0.327-8.81 \cdot T$ \\
\hline
\end{tabular}


TABLE II. EQUATIONS OF DENSITY AND SURFACE TENSION ISOTHERMS WITH THE LEAST SQUARE METHOD

\begin{tabular}{|c|c|c|}
\hline Temperature, ${ }^{\circ} \mathbf{C}$ & $\boldsymbol{\rho}, \mathbf{k g} / \mathbf{m}^{\mathbf{3}}$ & $\boldsymbol{\sigma}, \mathbf{N} / \mathbf{m}$ \\
\hline 350 & $\rho=11199-480 \cdot T$ & $\sigma=0.460-0.04 \cdot T$ \\
\hline 550 & $\rho=10941-489 \cdot T$ & $\sigma=0.438-0.04 \cdot T$ \\
\hline 650 & $\rho=10656-487 \cdot T$ & $\sigma=0.413-0.04 \cdot T$ \\
\hline
\end{tabular}

IV.

\section{CONCLUSION}

Density and surface tension of lead and five $\mathrm{Pb}-\mathrm{Na}$ alloys were studied as functions of concentration and temperature in the temperature interval from $350^{\circ} \mathrm{C}$ to $650^{\circ} \mathrm{C}$.

Addition of small percentages (up to 4 mass. \%) of sodium to the lead base significantly reduces the density and surface tension of the lead alloys. The form of the density and surface tension polytherms points as a negative thermal coefficient. For $\mathrm{Pb}-\mathrm{Na}$ alloys with more than $4 \% \mathrm{wt}$, the density isotherms show a significant (ranging from $5 \%$ to $7.5 \%$ ) reduction.

\section{References}

[1] M.M. Gubzhokov, Kh.N. Ibragimov, V.Z. Kanchukov, M.Kh Ponezhev, V.A. Sozayev, and A.I. Khasanov, "Influence of minor admixtures onto surface tension of lead", Melts, No 3, pp. 76-79, 2016.

[2] L.B. Director, A.Z. Kashezhev, I.L. Maykov, A.G. Mozgovoy, M.Kh. Ponezhev, and V.A. Sozayev, "Calculation complex for determination of thermophysical properties of liquids", Theses of reports from the Interdepartmental workshop on Technology of Alkali Liquid Metal Heat Transfer Fluids (Thermal Physics - 2009), 28-30 October 2009. p. 46-47.

[3] R.A. Khayrulin, S.V. Stankus, and R.N. Abdullayev, "Density and heat expansion of $\mathrm{Na}-\mathrm{Pb}$ liquid alloys with low led content", Thermal physics and aeromechanics, vol. 20, No 2, pp. 223-226, 2013.

[4] R.N. Abdullayev. Thermal properties of sodium-lead and potassiumlead liquid alloys, Novosibirsk: Institute of Thermal Physics named after S.S. Kutateladze, Siberian branch of the Russian Academy of Sciences.

[5] I.I. Zasorin, L.M. Kuznetsova, V.V. Kumskoy and others, "Studying the properties of sodium-lead alloy with the aim of selecting a firesafe heat transfer medium", Issues in Nuclear Science and Technology. Series: Nuclear Reactor Physics, No 4, pp. 72 - 77, 2008.

[6] V.Z. Kanchukoyev, "Determining the profile of a liquid drop on a hard surface", Letters to the Journal of Thermal Physics, vol. 30, No. 2, pp. $12-16,2004$

[7] L.B. Direktor, V.N. Zaychenko, and I.L., Maykov, "An improved sessile drop method for determination of surface tension of liquids, TVT", vol. 48, No. 2, pp. 193-198, 2004.

[8] A.F. Stalder, G.Kulik. D. Scenge. et. al. " Colloids and Surfaces A": Physicochem. End. Asp., vol. 286, p. 92, 2006.

[9] V.A. Konstantinov, "Surface tension, structure and microhardnes of lead-potassium, lead-sodium and lead-calcium alloys", Author's abstract... for a Candidate degree in Physical and Mathematical Sciences. Moscow: Moscow State University, 1950.

[10] V.K. Semenchenko. Surface phenomena in metals and alloys. Moscow: Gostekhizdat, 1957. 